\title{
The Movement and Sport Science in Italy Towards the European Research Council
}

\author{
Authors' contribution: \\ A) conception and design \\ of the study \\ B) acquisition of data \\ Gaetano Raiola \\ C) analysis and interpretation \\ of data \\ D) manuscript preparation \\ E) obtaining funding \\ University of Salerno, Italy
}

ABSTRACT

KEYWORDS

European Research Council Executive Agency, (ERCEA), has the mission to encourage the highest quality research in Europe through competitive funding and to support investigator-driven frontier research across all field, on the basis of scientific excellence. In 2019, European Research Council (ERC) updates the Panel Structure in 3 areas: Social Sciences and Humanities SH, Physical Sciences and Engineering PE, Life Sciences LS, 25 panels and 333 sub-panels. Every UE countries are updating own academic body system to align to the ERC. In Italy, this alignment is not possible because Movement and sport science has been together place SH and LS as academic disciplines of Physical training and Sport sciences. This is the vexata quaestio that makes the Italian academic system different from the other EU countries with consequences on the development of Italian research in Europa. Historical review explains why this division exists and why it begun after the second great war and developed to nowadays, determining an atypical model than others European countries. Movement and sport science should to be reasonably placed in an unique scientific area or alignments coherently at the related subpanels according to the scientific evidences, even if they are placed in more ERC areas. Both options can be applied according to ERC thought to resolve the actual problem.

\section{Introduction}

European Research Council Executive Agency (ERCEA) has the mission to encourage the highest quality research in Europe through competitive funding and to support investigator-driven frontier research across all field, on the basis of scientific excellence. European Research Council, ERC updates the Panel Structure in 3 areas: SH Social Sciences and Humanities - PE Physical Sciences and Engineering - LS Life Sciences and the 25 panels but amount and denomination of the sub panels by increasing them to 333 (ERCEA, 2019). In Italy also, as well as in others European Union countries, the academic disciplines in university body have to update to align to the ERC scheme to concerns both the funding of research and the researcher' profiles, including theirs retained rights. Currently in Italy, Movement and sport science has been place in two different scientific areas: SH and LS; the related two academic disciplines are assembled in the Group of academic recruitment field and Academic recruitment field and have different title than to the two areas. Methods and teaching of physical and sport activities in SH and Physical training and sport science methodologies in LS. (Miur, 2015). The two Academic disciplines are identifiable into Teaching and methods of physical activities and Teaching 
and methods of sport activities, and take place in scientific of historical, philosophical, psychological and pedagogical sciences (Miur, 2000). Italian university body discusses about the model transformation to respond at the request from the scientific world and so, to align the Italian university model body at the others of the ERCEA. The Italian Government has to rearrange the university research model to interact effectively to university body of the other countries. Currently, the Italian university model has three hierarchical levels: Academic scientific discipline, the Academic recruitment field and Group of academic recruitment field and, finally, the 14 scientific areas of Italian National University Council (CUN) that was instituted by law no. 18, 16 January 2006. This model is very different to the European Research Council Panel Structure, thus there are the difficulties of evaluating Italian research projects for financing the Italian grant funding. The researchers have structured according to Academic disciplines that, compared to those of others European countries, needs, in addition, the appropriate equivalences among to the academic positions of Italian researchers and ones of EU. This double situation was generated the main case in Movement and sport science field because it is divided into two different scientific areas with opposing research methods and contents of knowledge. Pedagogydidactics educational framework in an area of human science, so-called no-bibliometric, and the Bio-medical framework in an area of life sciences, so-called bibliometric. This involves an exceptional scientific ubiquity with difficulties of research evaluation, of education and, finally, of recruitment and upgrading career of researchers. Regardless of the complexity problem, Movement and sport sciences field needs for stabilization and simplification in a unique area: Life sciences (bibliometric) or Social sciences and Humanities (no bibliometric) for an own scientific identity and properly place in academic structure. Which means that the health, sport performance and physical education PE have been evaluating and assessing together, without the different among them. From the quantitative point of view, that is the amount of the researchers of Movement and sport science, it should be noted that most of them are structured in bio-medical area and, therefore, the problem of the reduced number of researchers in physical and sport education research lines worsen the situation. So, it is the major criticality of the question, that is also found in the different translations of the titling of academic disciplines: when regarding health and education the title is Teaching and methods of physical and sport activities in $\mathrm{SH}$ and when regarding sport performance and assessment the title is Physical training and sport science in LS. So, the opportunity for the rearrangement and simplification of the academic structure is also an opportunity to resolve the detailed problem. Nowadays, the problem is to choose in which scientific area, the Movement and sport science, has to be placed or to distribute its specific contents in all sub panels according to ERC scheme. Thus, it needs to tell the origin of the actual university body and the development of it during the previously period. To clarify the reasons of phenomenon trough an historical path thath starts since the Italian kingdom to nowadays; to investigate the characteristics of physical education and the social context determined the specificity of scientific identity as an atypical model than the others European countries (D'Elia et al., 2018). The investigation method is theoretical-argumentative on based on the historical evidences. It needs to trace the logical path of the development of Movement and sport science through the consultation of all official documents with archive method. To retrace the essential steps from the normative genesis of the field of knowledge, starting from the Italian Kingdom before, the fascism period after and, finally, the second postwar. To describe the period between institution of the Higher Institutes of Physical Education with law no. 88, February, 9 1958, to reach the current topical point of transformation of the structure of the Academic alignment disciplines with the European Research Council Panel Structure. At the end, it treats the Movement and sport science perspective by passing through the CUN keywords (CUN, 2016) of academic disciplines and research domains.

\section{Short historical excursus from the begin of the Italian Kingdom to the first post-war period}

Before the first great war there were several aspects that give a meaningful since the kingdom of Italy on physical education. In 1878 Francesco De Sanctis is the promoter of a norm that opens the way to a teaching characterized by highly educational purposes even if the military nature of gymnastics remains; after having 
redefined the discipline, renaming it "educational gymnastics", which at the end of 1800 became "physical education", emanates a law no. 4442, July 7 1878, that deals entirely with the subject, which makes teaching of educational gymnastic in compulsory schools and which establishes the compulsoriness the teaching of educational gymnastic even for women in schools of all grades. This law states, however, that the programs are agreed on the basis of a close confrontation between the Minister of Education and the Minister of War, and decrees that the teachers are recruited from the military personnel. In the early years of the 20th century, it was made obligatory, at university students of any faculty who had aspired to a middle school diploma, to attend special master classes in physical education at the respective medical faculties, while the normal gymnastics schools of Rome, Turin and Naples were transformed into institutes of teaching for habilitation at the teaching of physical education. In 1923 there was a structural reform of the Italian school system developed by the neoidealist philosopher Giovanni Gentile in collaboration with the pedagogic Giuseppe Lombardo Radice; this law, established by the legislative decrees issued by the government virtue of the delegation conferred by Parliament, redraws the conceptual and operational structure that will characterize the Italian school formally until the beginning of the 20s. Specifically, although physical education occupies an interesting position within the strict pedagogical system of Gentile, since the education of the body is aimed at forming the moral character and the will of each student and the body is considered in its spiritual essence, it is spin off from secondary school programs, even if it continues to be present in the program for preparatory and elementary schools and magisterial institutes; providing that the pupils of all governmental schools and matched employees from the Ministry of Education will complete their physical education at the designated gymnastic and sportive clubs. During the Fascist period, therefore, the teaching of physical education, characterized by a strong nationalist and paramilitary ideological model, is assigned to extra-scholastic bodies (Ledeen, 1969), such as the National Body for Physical Education (ENEF), the National Opera Balilla (ONB) and the Italian Youth of the Littorio (GIL). The collapse of the fascist regime, in 1943, drags all party organizations with it: after twenty years, physical education returns to the Ministry of Education, in terms of discipline; the emancipatory process from the ideological-military models of the previous period is, however, slow and difficulty: the ascending and descending phases that alternate in this process are outlined thanks to an analysis of the meanings attributed to physical education in teaching programs and in disposals that have occurred over time. After the cessation of the Fascism, PE academies for about a decade, no institution took over its functions until the academic year 1952/1953, when the Institute of PE of Rome (ISEF) began to function. The establishment of similar statal institutions was also planned. On the basis of this provision, the following ISEFs were set up in Turin (1959), Naples and Bologna (1960), Florence (1963), Milan (1964), Palermo (1965), Perugia and Urbino (1967), of the Lombardia based in Milan and L'Aquila (1968). The regulation of the ISEFs included three-year courses of study divided into distinct male and female sections. At the end of these courses the students received a PE diploma, an academic qualification required for the teaching of PE in secondary schools. The second after war was a dark period for physical and sport education because there was an intense and long political reaction, totally replaced with respect to the previous regime. The physical and moral exaltation of the race, contained in the racial laws of the kingdom of Italy extended to all possible fields including that of PE and sport science, beyond as an instrument of military offense and of social and cultural segregation, was also a significant element which had also permeated layers of the society. The issue of physicality, performance and physical beauty linked to physical exercise had strongly deluded public opinion to such an extent that it did not suggest that this exaltation had contributed to bring in Italy to the brink of social abyss. With the change of regime and the consequent new political class, the concern of a return to the drifts of the past grew due to the fascination that the theme of a strong and vigorous body could still provoke. The new state apparatus, constituted in the new republican form, therefore relegated the physical and sport sciences to limbo waiting for better times with the conviction to remove the past conditioning and at the same time to reduce the understandable reactions to the disaster caused by the previous politics. Thus, began a period of absolute inertia, which lasted 13 years after the second great war, in which it was decided to rebuild the physical and sport education within the education and 
university without having however in any consideration the contribution that a physical education and culturally renewed sport could and should give. Everything was suspended and only in the elementary schools with the Ermini programs in 1955 there was a little bit presence of the physical activity even if it debased its specific and educational contents. In the other grades of schools PE was left to a state of total abandonment because it was entrusted to personnel unqualified, coming from other professions, through a direct call recruitment that did not provide any training at all. In 1958, thanks to the political acumen of the then Minister of Education, Aldo Moro, the PE subject was stabilized in secondary school (lower and high school), the organic role of the teachers of PE was constituted and, years after the abolition of the Academies of Rome and Orvieto, were instituted the Higher Institutes of Physical Education with the task of training the PE teachers. At the same time on the sport side of the field, the institutional political apparatus initiated the same action against to the physical and moral exaltation of the race fascism concept, appointing the liquidator commissioner (Giulio Onesti) of the Italian National Olympic Committee (CONI) the sport body endowed with legal personality with the law no. Law $\mathrm{n}$. 426 February, 16 1942. However, he did not comply with the mandate given to him and made the CONI reborn, depleting it of those principles and mechanisms characterizing the fascist period and consolidating its organizational and managerial aspects. The CONI became, in addition that the confederation of sports federations, also a real body in substitution of the Italian government by the development of sport tasks and financed with the economical governmental resources. Promoted the establishment of new national sports federations, strengthened the existing ones, instituted the sports promotion and was hierarchically structured with a self-sufficient regulation that ensured its complete autonomy from politics. It replaced the Italian government in the training of sports technicians, built and ran sports facilities and slowly with a progressive collaboration began to be an indispensable partner for the School. The Youth games, the Student championships and the special projects for PE in the Elementary/Primary school were carried out. From time CONI projects: Physical literacy and Sport class are the basis of physical and sport education in the Primary school. So, also for extra school activity the physical activity had an absolute stop in order to the past philosophy and social value. As it tells before, the act of birth of Movement and sport science after the Second world war was the law that established the Higher Institutes of Physical Education (ISEF). The law no. 88, February, 7 1958, in Title III article 22 et seq., instituted the higher institutes of PE of university degree. The institutes (11) were equalized to the only public, the one already existing in Rome, the only one that had specific funding from the government and that also subsequently retained the prerogative of a leading academic venue for Movement and sport science. As a result of the equalization, the ISEF issued three-year academic qualifications with legal value, called a diploma to distinguish them from the degree that at the time generally had a four-year course of study while having the same legal weight. Thus, in 1958, began the restart of physical education but with a different academic level to the athers subject in the school and in university system.

\section{The recent development}

Finally, after almost 40 years from 1958 the Italian Government and Parliament decided to reform the ISEF and Movement and sport science in same hierarchical level of the others field of knowledge so it ranked them in university status. The Government issued the Legislative Decree no. 178 May 8 1998, Transformation of Higher Institutes of Physical Education and establishment of Faculties and Degree and Diploma Programs in Movement and sport science, according to art.17, co. 115 of law no. 127, 1997. Thus, the two new Academic disciplines are established by the academic body: physical activity science and sport science, the first one addresses health and educational goal and the second one for the sport performance and evaluation and assessment.

M-EDF/01 - METHODS AND TEACHING OF PHYSICAL ACTIVITY is the sector, referable to the one called "sciences of physical activity" established by the legislative decree of May 8th 1998, n.178, deals with the development and teaching of theories, techniques and methods for general physical and motor education or aimed at typical groups or age classes: 
a) Theory and methodology of human movement

b) Theory, technique and didactic of physical activity for the developmental age

c) Theory, technique and didactic of physical activities for adulthood and elderly

d) Theory, technique and didactic of group activities, recreational and free time

e) Theory, technique and didactic of "adapted" physical and sport activities

f) Theory, technique and didactic of preventive and compensative physical education.

M-EDF/02 - METHODS AND TEACHING OF SPORTS ACTIVITY, instead, is he sector, referable to the one called "science of sport disciplines" established by the legislative decree of May 8th $1998 \mathrm{n} .178$, deals with the development of theories, techniques and methods for training and for the practice of different sports activities and evaluations/assessment of yields and athletic attitudes:

a) Theory and methodology of training

b) Theory, technique and didactic of individual sports

c) Theory, technique and didactic of team sports

d) Theory, technique and didactic of swimming sports

e) Methods of motor assessment and attitudinal in sport

f) Organization of the sport organisms.

Ministerial Decree no. 855 October 302015 determinate of the Academic recruitment field and Group of academic recruitment field aggregating on the basis of Academic disciplines, detailing the contents with specific declaratory according to the new scientific determination in order to recruit the researchers. As following there are 8 new sectors, larger than the Academic disciplines, and where the health, education, performance, evaluation and assessment are distinguished in others scientific fields and, there are others related scientific knowledge about the life sciences.

The group of academic recruitment field and academic recruitment field are the following:

1) PHYSIOLOGY 05 / D1: PHYSIOLOGY The sector is interested in the scientific and didactic-training activities .... Evaluate ..., the expenditure and energy needs, ... Analyze and evaluate the integrated functioning of the various organs and systems during motor and sport activities and in extreme environmental conditions.

2) EXPERIMENTAL AND CLINICAL academic recruitment field 05 / E1: Biochemistry General and Clinical Biochemistry. The sector is interested in scientific and educational-training activities .... Clinical Biochemistry and Clinical Molecular Biology study ... structural and dynamical biochemical parameters relevant in the ... field of motor and sport activities.

3) APPLIED BIOLOGY academic recruitment field 05 / F1: APPLIED BIOLOGY .... The sector also studies the cellular bases of physical activity, behavior and evolution. ...

4) HUMAN ANATOMY AND HISTOLOGY academic recruitment field 05 / H1 Human Anatomy and Histology ... studied anatomical knowledge applied .... of interest ... and of the sports sciences, of the movement and of the maintenance of the state of health.

5) GENERAL MEDICAL CLINIC academic recruitment field 06 / B1: INTERNAL MEDICINE ... The sector also has specific competence ... in the medicine of physical exercise and sport, ...

6) SPECIALISTIC MEDICAL CLINIC academic recruitment field 06 / D2: ENDOCRINOLOGY, NEPHOLOGY AND FOOD SCIENCE AND WELLNESS Areas of expertise are ... the pathophysiology and clinical ... of exercise and sport; ...

7) SANITARY PROFESSIONS AND APPLIED MEDICAL TECHNOLOGIES academic recruitment field 06 / N1: SCIENCES OF HEALTH PROFESSIONS AND APPLIED MEDICAL TECHNOLOGIES.... the sector is interested in scientific activity and didactic - training in the field of technique and clinical exercise and sports with particular regard to general physical and motor education and aimed at particular groups or age groups, to clinical studies for the development of theories, 
techniques and methods for the training and practice of different sports and activities evaluations of athletic performances and attitudes and organization and management professional health education and training

\section{8) 11 / D2: DIDACTICS, SPECIAL PEDAGOGY AND EDUCATIONAL RESEARCH}

The academic recruitment field is interested in scientific and didactic-training activities... In particular, it deals with research on issues of ... education to physical and sports activities.

In new rearrangement there are specifically further part of Movement and sport science regarding physiology, biochemistry, biology, anatomy, medicine, endocrinology that in origin they were the origin knowledge of Movement and sport science. It specifies many quantitative and experimental aspects and so, enlarges the scientific basis of the field. Just in $7^{\text {th }}$ sectors $06 / \mathrm{N} 1$ Sciences of health profession deeps itself the elements of Movement and sport science although it is not a properly knowledge field. In fact, the academic disciplines are also interested in the scientific and training didactic activity in the field of technique and clinical physical exercise and sports with particular regard to physical education and general physical activity and addressed to particular groups of people or age groups, to clinical studies for the development of theories, techniques and methods for the training and practice of different sports activities and evaluations of athletic performances and attitudes and the organization and professional management of physical education and training. Thus, the previously dichotomy between health and educational purpose on one side and sport performance and evaluation-assessment on other side is amended by the overdue legislation. Subsequently, it occurs another rearrangement/reorganization of academic disciplines in group of academic recruitment field and academic recruitment field for general needs and Movement and sport science can systematically be properly place (Table 1). Because, subsequently, as a result of the modify of the CUN expressed the prescribed opinion that placed the Movement and sport science in an only Group of academic recruitment field and Academic recruitment field and so Ministerial Decree 855 October 302015 appeared only 2 scientific declaratory of Movement and sport science: First of all in Biomedical scientific area, that includes every aspects of Movement and sport science and, secondly in Pedagogy one with just a replay of educational aspects.

Table 1. Academic recruitment fields declaratory

\begin{tabular}{|c|c|}
\hline Code and title & Academic recruitment field declaratory \\
\hline $\begin{array}{lr}\text { 06/N2: } & \text { PHYSICAL } \\
\text { EXERCISE } & \text { AND } \\
\text { SPORT SCIENCES }\end{array}$ & $\begin{array}{l}\text { The academic recruitment field is interested in the scientific and didactic-training activity in } \\
\text { the biochemical, biological, morphological, physiological and clinical fields related to the } \\
\text { development of theories, techniques and methods for training and for the practice of } \\
\text { different sports and motor activities and evaluations of performances and athletic attitudes. } \\
\text { Moreover, the academic recruitment field is interested in the scientific and didactic-training } \\
\text { activity in the field of technical and clinical of physical exercise, physical activity and sports } \\
\text { with particular regard to motor and physical education (both general and aimed at particular } \\
\text { groups or classes of age) and of the evaluations of the effects of the physical activity also } \\
\text { through bio-humoral and clinical parameters for the achievement of the well-being and } \\
\text { health, of the performances and of the athletic attitudes. Finally, the academic recruitment } \\
\text { field deals with the organization and professional and health management of physical } \\
\text { education and training, the educational goals of physical and sport activities and the related } \\
\text { teaching-learning processes, in formal and informal contexts that support them. }\end{array}$ \\
\hline
\end{tabular}

11/D2: DIDACTICS, The academic recruitment field is interested in scientific and didactic-training activities .... SPECIAL PEDAGOGY In particular, it deals with research on issues of ... education to physical and sports activities AND EDUCATIONAL RESEARCH

Source: own study.

In this way, it was adopted the bi-univocal solution for Movement and sport science: pedagogy/didactics in one hand and health, sport performance and wellness in other one. Currently in Italy, Movement and sport science 
has been place in two different scientific areas: SH Social Sciences and Humanities and LS Life Sciences; for this reason, the related academic disciplines inside the Academic recruitment field are entitled Methods and teaching of motor and sport activities in Social Sciences and Humanities, SH, and Physical training and sports sciences methodologies in Life Sciences, LS. Therefore, the previously dichotomy ascribable at different Academic disciplines (health and education at movement science and sport performance and evaluation/assessment at sport science), is moved to two new Academic recruitment fields. Particularly, health performance evaluation assessment is in declaratory of 06/N2 Physical training and sport science in life sciences area while education is in declaratory of 11/D2 Didactics special pedagogy and educational researches in social science and humanities. So, the new arrangement/reorganized in Italian academic body for the Movement and sport science field amplifies the differences to the ERC scheme. CUN tries to simplify the complexity of the academic organization about the Academic disciplines and the Academic recruitment field elaborating series of keywords as a tool for declination simpler and wider than the declaratory of Academic disciplines on scientific issues. CUN, September 28 2016, carried out a "Proposal of a list of keywords, in Italian and English, on the scientific-disciplinary indicators useful for identifying the profile. These keywords have the aim to take in relationship ERC scheme and the Italian Academic disciplines. From the list of the 2400 keywords developed by the CUN, those linked to the essence of movement and sport knowledge were chosen (Table 2). Moreover, from the list have been chosen those related ones in a logic of strict link with the essential ones for Movement and sport science. They are with an alphabetical number in the Italian and English mother tongue.

Table 2. 21 CUN Keywords strictly related to Movement and sport science

\begin{tabular}{lll}
\hline $\begin{array}{c}\text { Number } \\
\text { order }\end{array}$ & \multicolumn{1}{c}{ Italian } & English \\
\hline 33 & ALIMENTAZIONE & NUTRITION \\
35 & ALLENAMENTO & PHYSICAL TRAINING \\
109 & APPRENDIMENTO & LEARNING \\
185 & BENESSERE & WELLBEING \\
201 & BIOCHIMICA GENERALE E & GENERAL BIOCHEMISTRY AND \\
& METABOLISMO & METABOLISM \\
209 & BIOINGEGNERIA & BIOENGINEERING \\
225 & BIOMECCANICA & BIOMECHANICS \\
411 & CONTROLLO & CONTROL \\
501 & DIDATTICA DELLE ATTIVITA' MOTORIE & HUMAN MOVEMENT AND SPORT \\
& E SPORTIVE & EDUCATION \\
550 & DIRITTO DELLO SPORT & SPORT LAW \\
613 & DOPING & DOPING \\
705 & EPISTEMOLOGIA & EPISTEMOLOGY \\
710 & ERGONOMIA & ERGONOMICS \\
835 & FISIOLOGIA DEL MUSCOLO & MUSCLE PHYSIOLOGY \\
845 & FITNESS MEDICINA DEL BENESSERE & FITNESS \\
1335 & MEDICINA DELLO SPORT & SPORT MEDICINE \\
1616 & PEDAGOGIA DELLO SPORT & SPORT PEDAGOGY \\
1688 & PRESTAZIONE SPORTIVA & SPORT PERFORMANCE \\
1784 & PSICOLOGIA DELLO SPORT & SPORT PSYCHOLOGY \\
1933 & SCIENZE DELL'ESERCIZIO E DELLO & PHYSICAL TRAINING AND SPORT SCIENCES \\
2253 & SPORT & \\
\hline SVILUPPO MOTORIO & MOVEMENT DEVELOPMENT \\
\hline
\end{tabular}

Source: own study.

ERC Panel Structure 2019 aims to do more than simply fund research. It looks to substantially strengthen and shape the all European research system. This is done through high quality peer review, the establishment of international benchmarks of success, and the provision of up-to-date 
information on who is succeeding and why. So, understanding the new system is essential. The basis on which to develop the reflections is the recent document of the composition of the scientific areas of the classification of "knowledge" as defined. The ERC scheme is composed of 3 main areas: Social and Humanities Sciences, Physical Sciences and Engineering and Life Sciences with a series of panels respectively in the number of 6 for Social and Humanities Sciences, 10 for Physical Sciences and Engineering and 9 for Life Sciences. The simplification is maximum since for each panel there are 333 subpanels structured in specific panels, that is a pyramidal structure where on the basis there are the wide classification of Knowledge and the apices there are the 3 scientific areas. The application of this classification leads to a specific result of an analytical, deductive and comparative process along the subpanels such as the descriptors/keywords with those inherent to the Movement and sport science. Specifically, the areas identify human and social sciences with the initials $\mathrm{SH}$ (Social Humanities), physical sciences and engineering PE (Physical Engineering) and life sciences with the initials LS (Life Science). Following are the respective panel of the 3 areas as the following scheme where there are only subpanels strictly coherent to the Movement and sport science (Table 3).

Table 3 - The ERC Area, panel and sub panel structure related Movement and sport science

\begin{tabular}{|c|c|c|}
\hline Area & Panel & Sub-panel \\
\hline \multirow{8}{*}{$\begin{array}{l}\text { SOCIAL } \\
\text { SCIENCES and } \\
\text { HUMANITIES }\end{array}$} & SH3 The Social World, Diversity, Population & SH3_9 Health ... \\
\hline & & SH3_11 ..., curriculum studies, educational \\
\hline & & policies \\
\hline & SH4 The Human Mind and Its Complexity & SH4_1 Cognitive basis of human development \\
\hline & & and educational, $\ldots$ \\
\hline & & SH4_5 Attention, perception, action, \\
\hline & & SH4 6 Learning, .... \\
\hline & & SH4_13 ... epistemology \\
\hline \multirow{14}{*}{$\begin{array}{l}\text { PHYSICAL } \\
\text { SCIENCES and } \\
\text { ENGENEERING } \\
\text { LIFE SCIENCES }\end{array}$} & PE6 Computer Science and Informatics & PE6_6 ......, algorithmic game theory \\
\hline & & PE6_8 ....., computer games \\
\hline & & PE6_13 Bioinformatics, ... \\
\hline & LS1 Molecular Biology, Biochemistry, Structural & LS1_2 Biochemistry and metabolism \\
\hline & Biology and Molecular Biophysics metabolism & \\
\hline & LS4 Physiology, Pathophysiology and & LS4_1 Organ physiology, ... \\
\hline & Endocrinology & LS4_5 Metabolism, \\
\hline & LS5 Neuroscience and Neural Disorders & $\begin{array}{l}\text { LS5_4 Sensation and perception (e.g. sensory } \\
\text { systems, sensory processing, pain) }\end{array}$ \\
\hline & & LS5_5 Neural bases of cognitive processes \\
\hline & & LS5_6 Neural bases of behaviour \\
\hline & & LS5_9 Neurotrauma and neurovascular \\
\hline & & $\begin{array}{l}\text { conditions (including injury, blood-brain barrier, } \\
\text { stroke, neurorehabilitation) }\end{array}$ \\
\hline & LS7 Applied Medical Technologies, Diagnostics, & LS7_8 Public health \\
\hline & Therapies, and Public Health & LS7_10 Health care research, ...... \\
\hline
\end{tabular}

Source: own study.

\section{Movement and sport science perspective}

To introduce the perspective of Movement and sport science as a function of a definitive arrangement/reorganization of "knowledge", it is useful to grasp the significant elements of the study and to make a synthesis in order to obtain a construction that can be convincing in used method and obtained results. To grasp in the sign of a single declaration of the Movement and sport science, two approaches can be proceeded:

a) Declining the contents of "knowledge" and also the methods of research, if different than the research traditions of the scientific area 
b) Following the document evolution by specifying the type of sources:

1) Synthesis of the declaratory of academic disciplines of Movement and sport science,

2) Evolution of the content of Group of academic recruitment field and Academic recruitment field,

3) Collation of the CUN keywords, and finally

4) Collation to ERC Panel Structure 2019. The highest regulatory act of rank with the contents characterizing the scientific identity and which has the most distant backdating is, without a doubt, the law of ISEF Reform which has identified the two new Academic disciplines characterizing and for which the CUN it has determined the denotation in Methods and teaching of the physical activity and Methods and teaching of the sport activities and the subsequently connotation in very specific declaratory. It is from this document that we must start, the genesis of the scientific identity is the identification of specific topics grouped together and belonging to the Sciences of the physical activity and to the Sciences of the sports disciplines:

a) Theory and methodology of human movement (Gaetano, 2012, p. 4, Schimdt et al, 2018, p. 145), of the training (Meinel \& Schnabel, 1986, p. 39, Matveev, 1972, p. 123 Bompa \& Carrera, 2005, p. 25) on physical activity for developmental age (Arnold, 1988, p. 45)

b) Theory, technique and didactics of physical activities (Bernstein, 1967, p. 33) for the adult and elderly age of the "adapted" physical and sports activities and preventive and compensative physical education (Pisapia \& D'Isanto, 2018, Winnick \& Porretta, 2006, p. 77)

c) Theory, technique and didactics of physical activities and group sports (Teodurescu, 1985, 35), recreational and free time of groups included swimming sports (Tiziana, et al., 2017, p. 3, Bellotti \& Zanon, 2008, p. 154)

d) Assessment and evaluation methods (Raiola, 2019, p. 6, D’Isanto et al., 2019, p. 3, Zatsiorsky \& Kraemer, 2016, p. 9) and attitudinal in sport (Tomas \& Nelson, 200, p. 87)

e) Organization of the sports organisms (De Iulis \& Pescante, 2004, p. 123).

These themes can be replaced by the CUN keywords selected for Movement and sport science field. As a second moment of synthesis it is advisable to merge the two existing declaratories and summarize one in application of the drastic simplification request. It could be declined with the same literal modality with which the CUN, from the birth of the Movement and sport science (1998) intended to identify them. The Academic disciplines deals with the development and teaching of theories, techniques and methods for general physical and sport education or aimed at particular groups or age groups and for the training and practice of different sports activities and of the performance evaluation/assessment and athletic aptitudes. This declaratory is strictly alleging to the Movement and sport science excluding the Academic disciplines that are affinities and instead are in the declaratory of the group of academic recruitment field and Academic recruitment field such as Anatomy, Physiology, Biochemistry, Biology, Medicine and Pedagogy.

\section{Academic disciplines by CUN keywords and research domains of ERC subpanels}

The main issue concerning the full and complete arrangement of "knowledge" with the European scheme is dealt with by the CUN systematically as a result of the mandate received from the Minister of University with the institution in the official nomenclature of disciplinary groupings replacing respectively of Academic disciplines, Group of academic recruitment field and Academic recruitment field and of the corresponding declaratory. In addition, the CUN also proposed the establishment of research domains also related to disciplinary groupings to fully align with the ERC scheme, which means Area, Panels and Subpanels. The scientific disciplinary groupings may also be of different research areas and may have various profiles so as to simultaneously guarantee the traditional investigative methodology of analyzing the detail and at the same time connecting them transversely with other details of other knowledge. They will have a code, a title and their own 
declaratory. Alongside the system of scientific disciplinary groupings, the CUN, identifies a taxonomy of research domains also transversal to disciplinary areas, to classify research activities in line with that used by the European Research Council. The research domains will be exclusively aimed at describing and managing research activities, in particular for what about the aspects related to the evaluation of research and projects. Each research domain will be articulated in a series of keywords, defined by the CUN and by the other institutional subjects of the university and research systems, which are representative of the cultural specificities of each study community, so that each researcher can identify those corresponding to the own research activity and community of reference. In the list of keywords may also include the denominations of the profiles used for the description of the disciplinary groupings and, to further delineate their research activity, a series of four to five keywords may be chosen, of who two to three taken from a set encoded used for the articulation of research domains, and another two-three proposal freely. The researcher will indicate, in accordance with the chosen keywords, his main research domain. However, keywords can also belong to different domains, in order to guarantee the possibility of highlighting interdisciplinary research activities. (CUN, 2018). For Movement and sports sciences, this arrangement of groupings and domains allows the same modifying treatment to other Academic disciplines, therefore the smallness of the number of university teachers will not weigh negatively as has happened up to now. The ongoing transformation will not take into account the number of structured researchers, but will be carried out only on the scientific identity of each academic disciplines and "knowledge".

Thus, Movement and sport science should to be reasonably placed in a unique area or, rearranged/reorganized and alignment coherently to the subpanels as well as related to them according to the documentary scientific evidences.

\section{Conclusions}

Both method options can be applied according to ERC thought. The way to complete alignment with the ERC scheme of knowledge facilitates the clarification underway for Movement and sport science which, being a young academic discipline in Italy is struggling to take off for the obstacles placed by the old researchers and the its academic lobby (Raiola, 2018; Raiola et al., 2018). The definitive scientific identity of Movement and sport science in Italy will have to be achieved also following a downsizing of the Italian National Olympic Committee CONI which carries out its role as manager of sports activities from the position of public body, as if it were a real Ministry of Sport. Of course, research and training are also affected by the action of CONI, which also commits public human and economic resources.

\section{Ethics approval and informed consent}

Manuscripts reporting studies on human subjects, human data or tissue, or animals should include a statement on ethics approval and consent when humans are involved. Please include the name of the committee that approved the study and reference number if appropriate.

\section{Competing interests}

The author Gaetano Raiola declares that the paper submitted to Physical Culture and Sport. Studies and Research are required to complete a declaration of competing interest for any commercial associations or financial interests held by the author.

\section{REFERENCES}

Arnold, P. (1988). Education, movement and the curriculum. London: Falmer press. 
Bellotti, P., \& Zanon S. (2008). Storia del concetto di allenamento /History of the concept of training/. In M. Calzetti, P. Bellottin\& S. Zanon (Eds.), Storia del movimento umano /History of the human movement/(p. 422). Perugia, Italy: Calzetti Mariucci.

Bernstein, N.A. (1967). The co-ordination and regulation of movements. Oxford: Pergamon Press.

Bompa, T., \& Carrera M.C. (2005). Periodization training for sports. Champaign, IL: Human Kinetics,

D'elia, F., Mazzeo, F., \& Raiola, G. (2018). The core curriculum in the university training of the teacher of physical education in Italy. Journal of Human Sport and Exercise, 13, 413-420.

D'Isanto, T., D'Elia, F., Raiola, G., \& Altavilla, G. (2019). Assessment of sport performance: theoretical aspects and practical indications. Sport Mont, 17(1), 79-82. doi: 10.26773/smj.190214

De Iulis, A., \& Pescante M., (2004). Storia dell'educazione fisica e dello sport/History of physical education and sport/. Roma: Monnier.

European Research Council Executive Agency (2019). Panel structure, Brussels: European Commission. Retrieved date from https://erc.europa.eu/sites/default/files/document/file/ERC_Panel_structure_2019.pdf

Gaetano, R. (2012). Motor learning and didactics into physical education and sport documents in middle school-first cycle of education in Italy. Journal of Physical Education and Sport, 12 (2), 157-163.

Italian Law no. 88, 7 febbraio 1958 Istituzione degli Istituti Superiori di Educazione Fisica /Establishment of Higher Institutes of Physical Education/.

Italian Law no. 16, January 16 2006, Riordino del Consiglio Universitario Nazionale /Reorganization of the National University Council/.

Italian law Law no. 426, February 16 1942, Costituzione e ordinamento del comitato Olimpico Nazionale Italiano /Constitution and organization of the Italian National Olympic Committee/.

Italian Law no. 4442, July 7, 1878, Obbligatorietà dell'insegnamento della ginnastica educativa nelle scuole /Mandatory teaching of educational gymnastics in schools/.

Italian Legislative Decree no. 178 May 8 1998, Transformation of Higher Institutes of Physical Education and establishment of Faculties and Degree and Diploma Programs in Movement and sport science, according to art.17, co. 115 of law no. 127,1997

Italian National University Council CUN (2016). Keywords list. Retrieved 12 June 2020 from https://www.cun.it/documentazione/cun-keywords/

Matveev, L. (1972). Periodisierang des sportichen training /Periodic ranking of sporting training/. Berlin: Berles end Wernitz.

Matveev, L. (1977). Fundamentals of sport training. Moscow: Fizkultura i Sport.

Meinel, G., \& Schnabel G. (1984). Teoria del movimento /Movement theory/. Roma: Società stampa sportive.

Minister of Education, University and Research, (2015). Ministerial decree no. 855, 30 October 2015.

Minister of Education, University and Research, (2000). Ministerial decree, 4 October 2000.

Raiola, G. (2019) Complex study for an epistemology of exercise and sport sciences: A)key concepts of both ERC subpanels and CUN keywords; b) physical training and sport methodology sciences academic disciplines in pedagogy recruitment sector and biomedical one: A correlationships study. Journal of Physical Education and Sport, 19, suppl. 5, 1748 - 1754 .

Pisapia, F., \& D'Isanto, T. (2018) Inclusive methods of adaptive training in sprints: A theoretical preliminary study. Journal of Physical Education and Sport, 18, 2101-2105.

Raiola, G., D'Elia, F., \& Altavilla, G. (2018). Physical activity and sports sciences between European Research Council and academic disciplines in Italy. Journal of Human Sport and Exercise, 13, 283-295.

Teodurescu, L. (1985). Teoria e metodologia degli sport di squadra /Team sports theory and methodology/. Roma: Società Stampa Sportiva,

Tomas, J.R., Nelson J.K., \& Silverman S. J. (2005). Research method in physical activity (4 ${ }^{\text {th }}$ edition). Champaign: Human Kinetics

Schmidt, R., Lee T., Winstein, C., Wulf, G., \& Zelaznik, H. (2018). Motor control and learning. Champaign IL: Human Kinetics

Tiziana, D., Antonetta, M., \& Gaetano, A. (2017). Health and physical activity. Sport Science, 10 (1), 100-105.

Winnick, J. \& Porretta D, (2006). Adapted-Physical-Education-and-Sport-6th-Edition. Champaign IL: Human Kinetics. 
Zatsiorsky, V.M., \& Kraemer, W.J. (2016). Science and practice of strength training. Second Edition. Champaign IL: Human Kinetics.

\section{AUTHOR'S ADDRESS:}

Gaetano Raiola

University of Salerno

Via Giovanni Paolo II

132 84084, Fisciano

Salerno, Italy

E-mail: graiola@unisa.it

Received: 29 December 2018; Accepted: 28 November 2019 